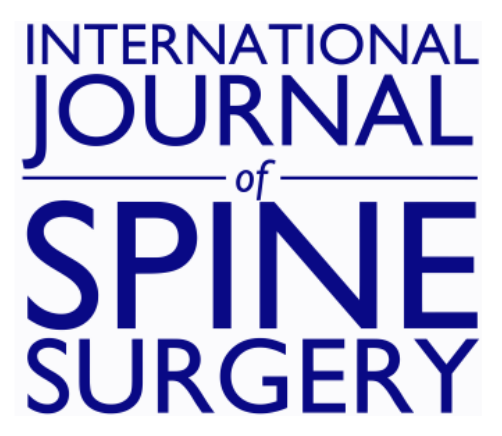

\title{
Treatment of Low Back Pain by Treating the Annular High Intensity Zone (HIZ) Lesions Using Percutaneous Transforaminal Endoscopic Disc Surgery
}

SREEDHARAN NAMBOOTHIRI, SATHISHCHANDRA GORE and GANESH VEERASEKHAR

Int J Spine Surg 2018, 12 (3) 388-392

doi: https://doi.org/10.14444/5045

http://ijssurgery.com/content/12/3/388

This information is current as of April 26, 2023.

Email Alerts Receive free email-alerts when new articles cite this article. Sign up at: http://ijssurgery.com/alerts 


\title{
Treatment of Low Back Pain by Treating the Annular High Intensity Zone (HIZ) Lesions Using Percutaneous Transforaminal Endoscopic Disc Surgery
}

\author{
SREEDHARAN NAMBOOTHIRI, PE, ${ }^{1}$ SATHISHCHANDRA GORE, MS ORTHO, ${ }^{2}$ \\ GANESH VEERASEKHAR, MD ${ }^{1}$ \\ ${ }^{I}$ Department of Orthopaedics and Spine Surgery, Kovai Medical Center and Hospitals, Coimbatore, Tamilnadu, India, ${ }^{2}$ Endoscopic Spine Surgeon, Pune, India
}

\begin{abstract}
Background: The study design was a retrospective case series. The objective was to find the clinical success rate of percutaneous transforaminal endoscopic disc surgery in patients suffering from discogenic chronic low back pain who were showing high intensity zone (HIZ) with degenerated disc as the only abnormality in the magnetic resonance imaging (MRI). The HIZ in the posterior annulus in degenerated disc is recognized as a pain generator. There are only a few studies available in the literature addressing the effect of identification and treatment of HIZ in the chronic low back pain patient.

Methods: We retrospectively evaluated the case records of all the patients who were treated by percutaneous endoscopic disc surgery for relief of symptoms as determined by visual analog scale (VAS) score, Oswestry Disability Index (ODI), Mac Nab criteria, and the consumption of analgesics, who had the predominant symptom of chronic low back pain, and whose lumbar spine MRI showed degenerated disc with HIZ and no other cause of back pain, like facet joint arthritis or sacroiliac joint arthritis.
\end{abstract}

Results: A total of 23 patients were identified to include in the study. Mean preoperative duration of low back pain was 13.1 months. Mean follow up after the procedure was 29 months. At final follow up, 69.6\% of the patients were not taking any pain medicines, $17.36 \%$ were on frequent analgesic medicines, $13.04 \%$ were on occasional analgesics. There was statistically significant reduction in VAS at 6 weeks postop and final follow up after surgery and the ODI at final follow up; $82.6 \%$ of patients had an excellent/good outcome as per Mac Nab criteria. There were no complications or reoperations in any of the patients.

Conclusions: Visualization and ablation of the chronic annular pathology in HIZ may give an effective and minimally invasive treatment for one of the back pain causes.

Endoscopic Minimally Invasive Surgery

Keywords: chronic low back pain, high intensity zone, endoscopic ablation, annular tear

\section{INTRODUCTION}

The significance of high intensity zone (HIZ) in posterior annulus as visualized in $\mathrm{T} 2$ weighted magnetic resonance imaging (MRI) in patients with chronic low back pain is being actively discussed and evolving in the literature. ${ }^{1-6}$ The majority of the recent literature supports the significance of HIZ in patients with chronic low back pain. ${ }^{7}$ The histology of HIZ containing chronic inflammatory granulation tissue with active inflammatory and pain mediators and free nerve endings have been brought out in the recent studies. ${ }^{5,6}$ Peng et $\mathrm{al}^{5}$ did a histologic study of the discs with HIZ in patients undergoing interbody fusion. Recently, percutaneous endoscopic disc surgery has been used in treatment of discogenic low back pain, but not specifically for HIZ. ${ }^{8}$
The pathoanatomy of the chronic annular tear with granulation tissue inside and the subsidence of low back pain by ablating that using percutaneous endoscopic discectomy has been documented and emphasized by Yeung and Gore in their comprehensive article. ${ }^{9}$

We conducted a retrospective study to find out the effectiveness of percutaneous transforaminal endoscopic disc surgery in patients suffering from discogenic chronic low back pain and showing degenerated disc with HIZ as the only abnormality detected in the MRI.

\section{METHODS}

In our institute, 96 patients underwent percutaneous transforaminal endoscopic disc surgery from 


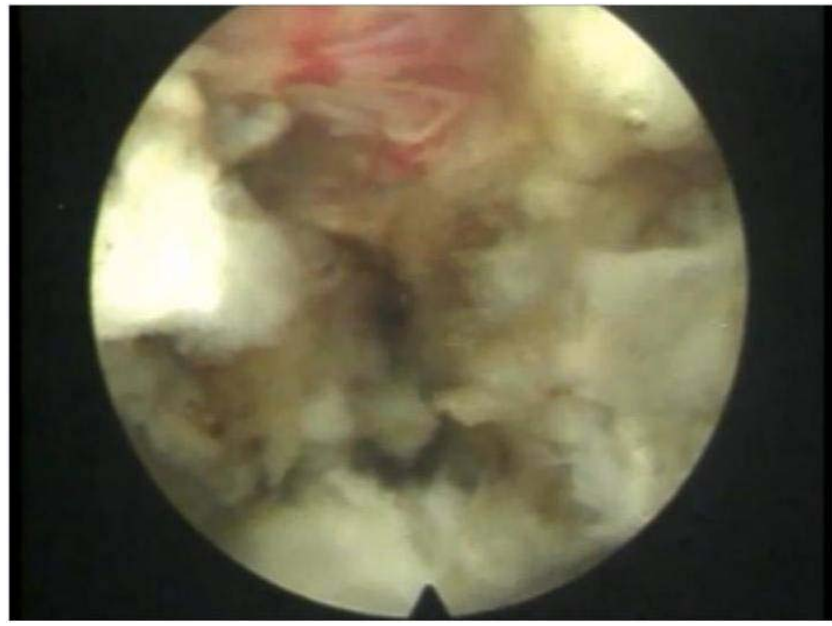

Figure 1. Endoscopic view of the granulation tissue in the posterior annulus.

December 2009 to November 2012. From those, we selected the patients for this study who fulfilled the following criteria: Patients who had the predominant symptom of low back pain for a minimum period of 3 months and who were not satisfied with conservative therapy, including analgesics (nonsteroidal anti-inflammatory drugs [NSAIDs] or tramadol and paracetamol in patients who cannot tolerate NSAIDs) and physiotherapy, and whose MRI showed degenerated disc with HIZ as the only abnormality. Patients who completed a minimum of 1 year of follow up was one of the inclusion criteria to find out any sustained pain relief and the development of any untoward effects, like a disc prolapse through the annular rent or instability. A minimum of 1 year of follow up was also the selected criteria by other researchers in endoscopic spine surgery. ${ }^{10}$

We excluded the patients who had HIZ and also had other pathology, like facetal or sacroiliac joint arthritis, endplate changes, vertebral hemangiomas, instability, osteoporosis, or deformity.

The patients were treated by percutaneous endoscopic disc surgery under local anesthesia with identification of the annular lesion as seen in the MRI and its ablation using radiofrequency or laser (Figures 1 and 2). All the procedures were performed by the corresponding author (SN) in a single institution.

The technique we followed is essentially the same described by Yeung et al. ${ }^{10}$ The procedure was done under local anesthesia supplemented with conscious sedation using fentanyl and midazolam. The patient was placed prone on a radiolucent table using 2 bolsters and biplanar imaging. A C-arm image

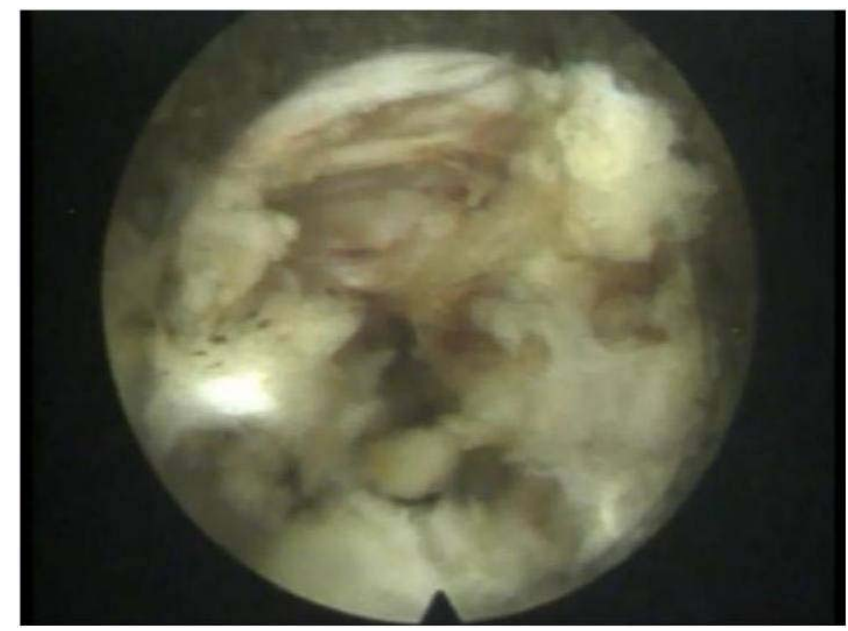

Figure 2. Endoscopic view of the posterior annulus after ablation of the granulation tissue with radiofrequency.

intensifier was used to guide an $18 \mathrm{G}$ spinal needle to the posterior annulus. We used a lateral skin entry portal about 13 to $14 \mathrm{~cm}$ from midline at about $20^{\circ}$ from the horizontal in order to have access to the more midline part of the posterior annulus.

The point of annular penetration was in the medial pedicular line. As soon as the needle touched the annulus, $1 \mathrm{~mL}$ of $0.5 \%$ lignocaine was infiltrated around the annular entry site. A guide wire was passed through the needle and a trocar passed over the guide wire into the disc, over which a beveled 8 $\mathrm{mm}$ cannula was introduced. The $25^{\circ}$ working channel endoscope was passed intradiscally and the posterior annulus inspected.

After removing any loose disc fragments created by the introduction of the cannula, the annular tear and granulation tissue was identified. The granulation tissue in the posterior annulus was seen as reddish areas with bleeding small vessels. The same was treated with low-dose laser ( 5 to $10 \mathrm{~W}, 20 \mathrm{~Hz}$, single-pulse mode) or bipolar radiofrequency with a digital setting of 30 in the coagulation mode. A 3- to 5-second application coagulated the vessels and the surrounding inflammatory tissues. The probe was changed to a nearby area then.

The patients were discharged on the next postoperative day and gradually returned to nearly full physical activity over a period of 6 weeks. They were not allowed to bend and lift weights for a minimum of 3 weeks postoperatively.

It is not our practice to do postoperative MRI routinely, the reason being the difficulty in our setting to convince a satisfied patient for an 
Table 1. Demographic and baseline characteristics of intervention group.

\begin{tabular}{ll}
\hline Characteristic & \multicolumn{1}{c}{ Values (n= 23) } \\
\hline Age, y (mean) & 47.78 \\
Female, no. (\%) & $13(56.5 \%)$ \\
Male, no. (\%) & $10(43.5 \%)$ \\
Smoker, no. (\%) & $5(21.7 \%)$ \\
Alcoholism, no. (\%) & $4(17.3 \%)$ \\
Diabetes, no. (\%) & $14(60.8 \%)$ \\
Hypertension, no. (\%) & $7(30.4 \%)$ \\
Ischemic heart disease, no. (\%) & $1(4.3 \%)$ \\
Physically demanding occupation, no. (\%) & $16(69.6 \%)$ \\
Sedentary (office type) occupation, no. (\%) & $7(30.4 \%)$ \\
Preoperative VAS score mean & $7.27($ range 6.1 to 8.3$)$ \\
Preoperative ODI score mean & $45.27 \%($ range 26.60 \\
& to $66.60 \%)$ \\
\hline
\end{tabular}

Abbreviations: ODI, Oswestry Disability Index; VAS, visual analog scale.

expensive investigation. Moreover, postoperative changes cannot be distinguished from granulation tissue in the noncontrast MRI. The follow-up assessment points were fixed as 6 weeks postprocedure and the last follow up to know the early result and the sustained effect on pain relief.

Any complications recorded perioperatively or during the follow up were noted. In endoscopic surgery, neurovascular injury, dural tear, and infection (discitis) are possible perioperatively, though rare. In the follow-up period, instability and a disc prolapse due to the annular rent are possibilities. The outcome assessments were done independently by our outpatient nursing assistant.

During the period December 2009 to November 2012, a total of 96 patients underwent percutaneous endoscopic disc surgery for predominant radicular pain or predominant back pain. Out of the total 96, 37 patients were operated for predominant low back pain. As per file records, 26 of these 37 had HIZ in the posterior annulus. Of the 26 patients, 3 were excluded as the duration of their follow up was less than 12 months ( 2 of them were followed up for 6 weeks and were completely painless at that time. One of them was followed for 7 months and had persistent pain and was on continuous analgesic medicines though maintaining the same level of activity); 23 remained for the analysis.

Table 2. Duration of pain before procedure and duration of follow up after treatment.

\begin{tabular}{lcr}
\hline & $\begin{array}{c}\text { Mean } \pm \text { SD } \\
(\text { Mo) }\end{array}$ & $\begin{array}{c}\text { Range } \\
\text { (Mo) }\end{array}$ \\
\hline Duration of pain before treatment & $13.1 \pm 15$ & $3-50$ \\
Duration of follow up after the procedure & $29 \pm 8.5$ & $12-41$ \\
\hline
\end{tabular}

Table 3. Outcomes as measured by Mac Nab criteria.

\begin{tabular}{lcc}
\hline Mac Nab Criteria & $\begin{array}{c}\mathbf{6} \text { Wk, } \\
\text { No. (\%) }\end{array}$ & $\begin{array}{c}\text { Final } \\
\text { Follow Up, } \\
\text { No. (\%) }\end{array}$ \\
\hline $\begin{array}{l}\text { Excellent (no pain and full return to } \\
\text { work) }\end{array}$ & $13(56.5 \%)$ & $15(65.2 \%)$ \\
$\begin{array}{l}\text { Good (occasional back pain interfering } \\
\text { with normal work) }\end{array}$ & $10(43.5 \%)$ & $4(17.4 \%)$ \\
$\begin{array}{l}\text { Fair (better than preoperative status } \\
\text { but has to modify work due to pain) }\end{array}$ & $0(0 \%)$ & $4(17.4 \%)$ \\
\hline
\end{tabular}

We have used the following outcome measures: Mac Nab criteria for relief of back pain and return to work, the 11 point ( 0 to 10 ) visual analog scale (VAS) score for pain, and the Oswestry Disability Index (ODI) Version 2.0 (the section on sex was omitted as the study population was not willing to discuss sexual activity due to social custom) for improvement in the daily activities.

In addition, the consumption of analgesics was also considered as an indirect measure of pain. We consider a $50 \%$ reduction of VAS score or ODI and an excellent/good Mac Nab outcome as a successful clinical outcome.

\section{Statistical Methods}

We used the IBM SPSS version 20 software for analysis of the data. Paired sample $t$ tests were used for deriving the mean difference, percentage change, and SD change. For statistical tests, a $P$ value of .05 was taken as statistically significant.

\section{RESULTS}

There were 10 males and 13 females, mainly of a middle aged population (mean age $=47.78$ years). The majority $(69.6 \%)$ were engaged in physically demanding jobs, including household activities and working in the field (Table 1).

Patients suffering due to pain from 3 to 50 months were operated on. Mean preoperative duration of low back pain was 13.1 months. Patients were followed up for a minimum period of 12 months to a maximum of 41 months after the procedure. That is, their last follow-up assessment was from 12 to 41 months after the procedure.

Table 4. Outcomes as measured by visual analog scale (VAS) and Oswestry Disability Index (ODI).

\begin{tabular}{lcc}
\hline Outcome Measures $(\mathbf{n}=\mathbf{2 5})$ & Range & Mean \pm SD \\
\hline Postop VAS (6 wk) & $4.4-1.1$ & $2.75 \pm 0.94$ \\
Postop VAS last follow up & $4.5-0$ & $2.34 \pm 1.51$ \\
Postop ODI last follow up & $42.20-0 \%$ & $16.58 \pm 16.35 \%$
\end{tabular}


Table 5. Mean change and percentage change in outcome measures $(n=23$; paired sample $t$ tests).

\begin{tabular}{|c|c|c|c|c|c|c|}
\hline & $\begin{array}{c}\text { Preop } \\
\text { Mean } \pm \text { SD }\end{array}$ & $\begin{array}{l}6 \text { Wk Postop } \\
\text { Mean } \pm \text { SD }\end{array}$ & $\begin{array}{c}\text { Last Follow Up } \\
\text { Mean } \pm \text { SD }\end{array}$ & $\begin{array}{c}\text { Change } \\
\text { Mean } \pm \text { SD }\end{array}$ & $\begin{array}{l}\text { 95\% Confidence } \\
\text { Interval }\end{array}$ & $P$ Value \\
\hline VAS & $\begin{array}{l}7.28 \pm 0.79 \\
7.28 \pm 0.79\end{array}$ & $2.75 \pm 0.94$ & $2.34 \pm 1.51$ & $\begin{array}{l}4.52 \pm 0.7 \\
4.94 \pm 1.48\end{array}$ & $\begin{array}{r}4.22-4.82 \\
4.3-5.58\end{array}$ & $\begin{array}{l}<.001 \\
<.001\end{array}$ \\
\hline ODI & $45.27 \pm 12.91 \%$ & $2.75 \pm 0.94$ & $\begin{array}{c}2.34 \pm 1.51 \\
16.58 \pm 16.35 \%\end{array}$ & $\begin{array}{l}0.42 \pm 1.11 \\
28.7 \pm 11.3 \%\end{array}$ & $\begin{array}{l}(-) 0.06-0.9 \\
23.8-33.6 \%\end{array}$ & $\begin{aligned} & .08 \\
< & .001\end{aligned}$ \\
\hline
\end{tabular}

Abbreviations: VAS, visual analog scale; ODI, Oswestry Disability Index.

Mean follow up after the procedure was $29 \pm 8.5$ months (Table 2).

Nineteen $(82.6 \%)$ of the 23 patients had a good/ excellent outcome as per Mac Nab criteria at the last follow up. In short, they were able to return to the same level of activity as before the onset of pain (Table 3).

There was a decrease in mean VAS score from preop to 6 weeks follow up by $4.52 \pm 0.7$ points. These patients experienced a $61.17 \%$ decrease in VAS score from preop to 6 weeks postop (Tables 4 and 5). There was a decrease in mean VAS score from preop to last follow up by $4.94 \pm 1.48$ points. These patients experienced a $67.95 \%$ decrease in VAS score from preop to the last follow up, which was at least 12 months after the procedure (Tables 4 and 5).

When the mean VAS scores at 6 weeks and last follow up were compared, there was only a modest change $(0.42 \pm 1.11)$. There was a further improvement of only $15.27 \%$ in VAS score from 6 weeks after surgery to the last follow up at least 12 months after the procedure (Tables 4 and 5).

There was a decrease in mean ODI score from preop to the last follow up by $28.7 \pm 11.3 \%$. The percentage reduction in ODI from preop to postop was $63.39 \%$, when the follow-up assessment was done after a minimum of 12 months after the procedure (Tables 4 and 5).

At the last follow up, $16(69.6 \%)$ of the 23 patients were not taking any pain medicines; 4 $(17.36 \%)$ were on frequent analgesic medicines, more than 3 doses of analgesics a week; 3 (13.04\%) were on occasional analgesics, not more than 1 dose of analgesic in a fortnight.

There were no complications or reoperations in any of the study patients.

\section{DISCUSSION}

It seems beneficial to treat the chronic ulcerlike ${ }^{11}$ lesion of HIZ in the posterior annulus in patients with chronic low back pain by adequate debride- ment of the granulation tissue. Percutaneous endoscopic disc surgery is likely to provide effective motion-preserving treatment for these patients who are usually undertreated by neglect or overtreated by fusion surgery. The HIZ lesions are visualized while looking from inside the disc only, as they are covered by posterior longitudinal ligament (probably none of us noticed them while doing a discectomy even under the microscope). The use of endoscopy has thus a specific advantage in treating these lesions.

The strength of the study is that we used ODI as an outcome measurement, which is a validated measure for back pain. ${ }^{12}$ We also used VAS score and Mac Nab criteria to measure the outcome of treatment like other current authors. ${ }^{13}$

This study has some limitations. No comparison groups are available, and this is a retrospective case series. Though assessed independently, this was not a blinded study. The study is based on a small number of patients, largely due to the strict exclusion criteria. If the images showed any other abnormality, like facetal arthritis, instability or disc space collapse, or sacroiliac arthritis, that was not treated endoscopically.

The observation that VAS at 6 weeks versus final follow up is not statistically significant can be explained by the initial improvement due to the surgery in the majority of the patients.

However, there is a need for a well-controlled comparative study prospectively assessing the outcomes in a large number of patients before recommending this as the standard of care.

\section{ACKNOWLEDGMENTS}

We sincerely acknowledge the contribution of the following personalities towards the study and preparation of the manuscript: Dr $\mathbf{J}$ N Narayanan, MSc, MBBS, FRCA, Consultant Anesthesiologist, NHS Trust, UK; Mrs Gracy Yowan, Department of Orthopaedics, Kovai Medical Centre and Hospitals, Coimbatore. 


\section{REFERENCES}

1. Aprill C, Bogduk N. High intensity zone: a diagnostic sign of painful lumbar disc on magnetic resonance imaging. $\mathrm{Br}$ J Radiol. 1992;65(773):361-369.

2. Saifuddin A, Braithwaite I, White J, et al. The value of lumbar spine magnetic resonance imaging in the demonstration of anular tears. Spine (Phila Pa 1976). 1998;23(4):453-457.

3. Munter FM, Wasserman BA, Wu HM, et al. Serial MR imaging of annular tears in lumbar intervertebral disks. AJNR Am J Neuroradiol. 2002;23(7):1105-1109.

4. Resnick DK, Choudhri TF, Daily T, et al. Guidelines for the performance of fusion procedures for degenerative disease of lumbar spine. Part 6: magnetic resonance imaging and discography for patient selection for lumbar fusion. $J$ Neurosurgery Spine. 2005;2(6):662-669.

5. Peng B, Hou $\mathrm{S}, \mathrm{Wu} \mathrm{W}$, et al. The pathogenesis and clinical significance of a high-intensity zone (HIZ) of lumbar intervertebral disc on MRI imaging in the patient with discogenic low back pain. Eur Spine J. 2006;15(5):583-587.

6. Dongfeng $\mathrm{R}, \mathrm{Hou} \mathrm{S}, \mathrm{Wu} \mathrm{W}$, et al. The expression of tumor necrosis factor alfa and CD-68 in high intensity zone of lumbar intervertebral disc on magnetic resonance image in the patients with low back pain. Spine (Phila Pa 1976). 2011;36(6):E429-E433.

7. Jha SC, Higashino K, Sakai $\mathrm{T}$, et al. Clinical significance of high intensity zone for discogenic low back pain: a review. $J$ Med Invest. 2016;63(1-2):1-7.

8. Tsou PM, Alan Yeung C, Yeung AT. Posterolateral transforaminal selective endoscopic discectomy and thermal annuloplasty for chronic lumbar discogenic pain: a minimal access visualized intradiscal surgical procedure. Spine $J$. 2004;4(5):564-573.

9. Yeung AT, Gore S. In-vivo endoscopic visualization of patho-anatomy in symptomatic degenerative conditions of the lumbar spine II: intradiscal, foraminal and central canal decompression. Surg Technol Int. 2012;21:299-319.
10. Yeung AT, Tsou PM. Posterolateral endoscopic excision for lumbar disc herniation: surgical technique, outcome and complications in 307 consecutive cases. Spine. 2002;27(7):722-731.

11. Ogunbiyi OA. Cysts, ulcers and sinuses. In: Russel RCG, Williams NS, Bulstrode CJK, eds. Bailey and Love's Short Practice of Surgery. 24th ed. London: Edward Arnold (Publishers) Ltd; 2004:208.

12. Chapman JR, Hanson BP, Dettori JR, et al. Spine Outcome Measures and Instruments. Davos, Switzerland: AO Spine International; 2007.

13. Torres J, James AR, Alimi M, et al. Screw placement accuracy for minimally invasive transforaminal lumbar interbody fusion surgery: a study on 3-D neuronavigation-guided surgery. Global Spine J. 2012;2(3):143-152.

Disclosures and COI: The authors declare that there is no conflict of interest regarding the publication or content of this paper.

Corresponding Author: Sreedharan Namboothiri, PE, Department of Orthopaedics and Spine Surgery, Kovai Medical Center and Hospitals, Avanashi Road, Coimbatore, Tamilnadu, India. Phone: 091422 4323101; Mobile: 091 9488458713, 091 8220979785; Email: endospines@ gmail.com.

Published 15 August 2018

This manuscript is generously published free of charge by ISASS, the International Society for the Advancement of Spine Surgery. Copyright @ 2018 ISASS. To see more or order reprints or permissions, see http://ijssurgery.com. 